\title{
A apreciação artística como experiência estética: entre os nós da sacralização da arte e do artista
}

\begin{abstract}
RESUMO: O presente estudo busca contribuir para o debate acerca do ensino da arte e um de seus principais papéis: o de proporcionar aos educandos experiências estéticas por meio da apreciação artística. O recorte proposto analisa os possíveis percalços desse caminho sob o prisma da sacralização da arte e do artista, entendida como fruto de um processo histórico-social de uma rede de relação que subtrai e mistifica a atividade criadora e sua apreciação. Este processo sacralizou as obras e os autores e também os membros licenciados para delas se apossarem. Além de legitimar o conceito de dom na criação artística - como forma de naturalizar e esconder as relações de dominação apresenta o discernimento estético como algo inato, impossível de ser ensinado. Cabe à escola um investimento massivo em ensinar a disposição culta, os códigos de leitura das obras que permitirão uma melhor experiência estética, sem esquecer de primar pelas "alegrias culturais".

PALAVRAS-CHAVE: Arte - Estudo e ensino. Arte - Apreciação.
\end{abstract}

Neste artigo, busco contribuir para o debate acerca do ensino da arte e um de seus principais papéis: o de proporcionar aos educandos experiências estéticas por meio da apreciação artística. O recorte proposto visa analisar os possíveis percalços desse caminho sob o prisma da sacralização da arte e do artista.

Para tanto, é necessário, em um primeiro momento, esclarecer ao leitor por meio de um breve conceito e esboço do contexto histórico o que vem a ser sacralização e o que entendo por apreciação artística como experiência estética. A reflexão segue tecendo comentários acerca dos efeitos da sacralização na atividade de apreciação para daí, então, apresentar os questionamentos para as quais busco respostas.

O termo sacralização é aqui formulado com base na leitura da obra de Pierre Bourdieu (1996a) e de Walter Benjamim (1994) aliados ao confronto com minha prática docente e discente de arte-educadora e pesquisadora da área.

A palavra sacralização vem de sacra, relativa às coisas sagradas, sacras. Sacralização, por sua vez, tem como terminação o sufixo ação, que evidencia processo, ação intencional com vista à transformação de algo. Assim, o termo sacralização refere-se ao processo, à ação de converter em sagrado, de consagrar.
Klésia Barbosa

Professora da Universidade Federal de Goiás

kesiamb@yahoo.com.b 
Quase tão antiga quanto o próprio homem, a sacralização surge com a necessidade que este demonstra de se ligar ao divino, sobrenatural e místico. Desde sua gênese, tudo o que se vincula ao sagrado começa já muito cedo a impor certas noções fundamentais, produto e condição do processo de sacralização: o privilégio e o elitismo. Estas são, pois, as faces constitutivas da sacralização. Para ser mais incisiva, a sacralização estabelece com essas facetas uma relação simbiótica à medida que torna os conhecimentos artísticos e a prática cultural desnecessários às camadas populares e um privilégio dos poucos eleitos e naturalmente dotados para esses fins. O privilégio e o elitismo nas artes são conceitos distintos; contudo, são condição e produto do funcionamento de uma rede complexa de relações que sacraliza a arte e o artista.

A sacralização é aqui considerada em dois grandes eixos: a sacralização da arte, que se refere à obra de arte eterna e intocável, ao elitismo no acesso e fruição artística e a sacralização do artista, que diz respeito à mistificação da atividade criadora e a existência de uma distância em relação ao artista e seu público.

A sacralização de que falo encontrou referência na Idade Média, palco ideal de todos os ingredientes que a tornaram mais perspicaz, totalizadora e emblemática da relação do público com a arte e o artista. Dessa forma, o termo sacralização designa o conjunto dos questionamentos percebidos na lida docente cotidiana e baseia-se na leitura e nas semelhanças que encontrei entre a sacralização vigente na Idade Média e a empreendida no campo da arte.

Nos diversos momentos históricos e com mais ênfase na Idade Média, o sagrado tem, em seu bojo constitutivo, as noções de absoluto, intocável, místico e incompreensível como eixo "identitário" de todas as esferas da vida. Nesse contexto, a grande maioria das pessoas era fadada a absorver uma religiosidade imposta em obediência inquestionável aos dogmas sagrados, em uma relação de respeito profundo e irrefletido. Embora as catedrais estivessem abertas, os conhecimentos que ali figuravam estavam interditos à plebe, à medida que sua compreensão se dava de maneira parcial e manipulada. Ao clero restava guardar as verdades ameaçadoras do status social vigente e alimentar a crença na mística e inacessibilidade do universo sagrado.

De maneira semelhante à sacralização desenvolvida no período medieval, a sacralização da arte e do artista também apre- 
senta todas essas noções " mostra-se absoluta em seus valores e consagrações, intocável à grande maioria das pessoas, permeada pela noção mística de dom, no que tange à apreciação e criação artística e incompreensível a reles profanos mortais. Assim, a grande maioria das pessoas trava com as artes a mesma relação de respeito infundado e irrefletido que ora manteve (ou ainda mantém) com a religiosidade "totalmente desprovida das infinitas possibilidades de recriação de significados estimulada pelo caráter polissêmico da obra de arte.

Hoje, os museus, galerias de arte e outros espaços de cultura "igualmente abertos e de livre acesso como as catedrais na Idade Média " encontram-se inacessíveis à maior parte da população que, desprovida dos códigos de leitura, vê-se impossibilitada de investir na prática cultural. Resta aos detentores estatuários das boas maneiras, aos homens egrégios da cultura erudita revestir com a aparência de natural o que conquistaram como resultado de uma aprendizagem sistematizada, ocultando as condições sociais de apropriação dos bens artísticos e emprestando à arte as mesmas noções irrevogáveis e inacessíveis do mundo divino, ou seja, sacralizando-a.

Para Bourdieu (1996b), cada campo social, incluindo aí o artístico, impõe aos agentes uma forma particular de regulação das práticas e representações, baseada em uma forma particular de illusio. A illusio é condição e produto do funcionamento do jogo, materializa uma crença coletiva no poder e no valor sagrado das apostas. No caso do campo artístico, isso se manifesta pela crença coletiva no valor da obra e do artista e permite a estes, quando consagrados, constituir certos objetos pelo milagre da assinatura. A illusio é fruto de uma rede de relações que consagra e mistifica a obra de arte e o artista, ao mesmo tempo em que cerceia e impede o contato da grande maioria das pessoas com a arte e o mundo da arte.

Walter Benjamim (1994), em seu texto O autor como produtor $^{1}$, de 1934, busca extirpar do artista toda a mística criadora e toda aura de mistério em torno do ato de criação ao concebê-lo como um trabalhador radicado em uma realidade material com em 27 de abril de 1934 recursos e técnicas determinados à disposição. Segundo Santaella (1995), o que Benjamim quer dizer é que, quando se trata de discutir problemas relativos ao estético e no momento em que os valores sagrados começam sorrateiramente a se insinuar, subita- 
mente o caráter de historicidade e concreção das produções humanas fica abalado e se esvai em discursos abstratos e nebulosos. Assim, o espectador/leitor/apreciador perde a possibilidade de ser colaborador e partícipe no significado das obras, que permanecem encobertas pelo manto dos valores sagrados e imutáveis.

O conceito de sacralização implica diretamente a compreensão do campo artístico e de como esse campo opera para transmitir aos seus agentes certos condicionamentos, sob a aparência do natural, e excluir a grande maioria da experiência estética, sob o forte argumento de que educação é algo inato.

Ao questionar a sacralização da arte e do artista, não estou querendo despir a prática cultural de um tipo de magia que lhe é inerente " como a magia suscitada pelo processo criativo, pela experiência estética crítica e arrebatadora, orgástica " capaz de propiciar ao homem sensações que não obterá em outras atividades. Ao contrário, é pela crença de que tais atividades e sensações são a essência da humanização que considero necessário questionar essa sacralização.

Sintetizando: a sacralização é fruto de um processo históricosocial de uma rede de relações que consagra e mistifica a obra de arte e o artista. Ao mesmo tempo em que assegura e recompensa a familiaridade de alguns com a arte e o mundo da arte, dificulta a democratização do acesso aos bens artísticos e mistifica a atividade criadora. Assim, o processo de sacralização gera, contraditoriamente, sua subtração do conjunto da vida.

Segundo Bourdieu (1982), a escola é um campo social que faz intersecção com outros campos sociais. Nesta medida, ao 1idar com o ensino de artes, algumas noções cristalizadas no campo específico das artes acabarão por acompanhar e determinar de certa maneira, o habitus dos atores educacionais. Entre professores e a comunidade escolar, em geral, a mística ilusão do gênio criador, todo-poderoso, e a roupagem elitista com que se reveste a atividade criadora estão contidas nos discursos tão sacralizados quanto a própria arte e o artista. Essa crença produzida no poder criador do artista e no caráter elitista da arte e da atividade criadora, contribui para a disseminação de concepções maniqueístas que polarizam e dividem os homens entre criadores e não-criadores, talentosos e pessoas comuns, dotados de compreensão estética e desprovidos desta, dignos das alegrias estéticas e não-dignos. 
O interessante é notar que esses mesmos atores, essa concepção sacralizada da arte e da cultura também a consideram " por força das concepções elitistas " coisa para poucos e felizes, artigo de luxo, acessório da cultura, atividade supérflua, requinte de distinção reservada ao cultivo do espírito das classes sociais mais ricas. Por isso a sacralização encerra ao mesmo tempo forças e fraquezas, conquistas e perdas, privilégios e exclusões, união e afastamento, valoração e desvalorização.

Em suma, as relações entre arte, artista e público sofreram, e ainda sofrem até hoje, os dolorosos efeitos do processo de sacralização, de forma que quase ninguém, letrado ou analfabeto, se dedica a desatar os nós ou a profanar o refúgio sacrossanto da arte e seu universo. Essa illusio produzida pelo campo artístico é tão sagaz que cria para a maioria das pessoas a sensação de que estão à margem do mundo da arte e da cultura e, ainda, legitima a ilusão segundo a qual a arte, por princípio, tenha nascido para a elite.(SANTAELLA, 1995, p.19)

Feitas as considerações necessárias sobre a sacralização da arte e do artista, é propício delimitar que o entendimento de arte por apreciação artística. As obras de arte expressam um pensamento, uma visão de mundo e provocam uma forma específica de inquietação no observador. Trata-se de uma sensação especial, uma vontade de contemplar, uma admiração emocionada ou uma comunicação com a sensibilidade do artista.(OLIVEIRA, 2001).

No contexto da apreciação artística como experiência estética, a sensibilidade e o racional não estão condenados a opor-se um ao outro, na verdade sensibilidade e emoção se unem ao racional e cada um dos dois elementos realça o outro. "A mais elevada alegria estética é sem dúvida a união da emoção com o saber".(SNYDERS, 1995, p.145). Explicando melhor: uma autêntica experiência estética depende, na mesma medida, da sensibilidade, da emoção do espectador e dos conhecimentos acerca daquele autor, seu estilo e seus códigos de leitura. Seria como diz a poesia de Elisa Lucinda A menina transparente: "ficar com o coração inteligente e o pensamento emocionado", numa indissociável união.

Bourdieu (2003, p.110) salienta, em seu livro O amor pela arte, publicado pela primeira vez em 1966.

Contra a ideologia carismática que instala a oposição entre a experiência autêntica da obra de arte com 'afeição' do coração ou compreensão ime-

R. Faced, Salvador, n.12, p.139-150, jul/dez. $2007 \quad 143$ 
diata da intuição, por um lado, e, por outro, os procedimentos laboriosos e os frios comentários da inteligência, passando sob silêncio as condições sociais e culturais que tornam possível tal experiência e tratando, concomitantemente, como graça de nascimento a virtuosidade adquirida por uma longa familiarização ou pelos exercícios de uma aprendizagem metódica, a sociologia estabelece, do ponto de vista lógico e, ao mesmo tempo, experimental, que a apreciação adequada da obra cultural e, em particular, da obra de cultura erudita, pressupõe, a título de ato de decifração, a posse da cifra que serviu para codificá-la.

O amor pela arte não vem gratuitamente, tampouco é apreendido forçosamente com uma alfabetização estética, que dilacera a obra de arte e oferece fragmentos ao espectador. Ao contrário, esse sentimento é fruto de um gradual processo de familiarização artística, de aquisição de códigos de leitura e de um "engravidamento" do indivíduo da necessidade cultural. A apreensão da obra de arte, no entendimento de Forquin (1982), nunca é imediata; ela pressupõe uma informação, uma familiarização, uma freqüentação, "únicos elementos capazes de propiciar ao indivíduo esses esquemas, esses sistemas de referências, esse programa de percepção equipada, mais apto a criar no indivíduo o amor pela arte do que as efêmeras ou ilusórias paixões à primeira vista". (FORQUIN, 1982, p.44)

Com base nesses autores, considero a apreciação artística como experiência estética, fruto de um contato sistemático e prazeroso com as obras da cultura, em que as alegrias estéticas decorrem de um exercício de sensibilidade e iniciação ao conhecimento da arte. A experiência estética é, ao mesmo tempo, condição e produto de uma maior convivência com as artes e deve estar no centro da educação escolar em artes.

Agora, diante dessas considerações iniciais, resta saber: em que medida a sacralização da arte e do artista interfere na apreciação artística? Se ela realmente afeta/dificulta a experiência estética qual recurso caberia então para resgatar as alegrias estéticas? Esses questionamentos servirão muito mais para orientar reflexões acerca dessa problemática do que necessariamente para erigir respostas totalizadoras. Pretendo que tais reflexões, de alguma forma e em algum lugar, contribuam para abalar concepções arraigadas que consideram a cultura como privilégio da natureza.

Com a breve descrição do que vem a ser sacralização, já é possível perceber, ainda que preliminarmente, de que maneira a

144 R. Faced, Salvador, n.12, p.139-150, jul/dez. 2007 
apreciação artística estaria afetada por esse processo. Ao tornar os objetos de arte distantes objetos de culto, sacralizados em relação às massas, o espectador desenvolve um respeito quase canônico, que nada tem a ver com um sentimento de familiarização estética.

Esse respeito e admiração condicionadamente impostos às obras de arte sacralizadas são exemplarmente retratados em uma reportagem de um jornal local que intitula Em busca de Monalisa. O título já evidencia a grande e conhecida procura pela obraprima de Leonardo da Vinci, que, nos últimos dois séculos, tornou "uma espécie de peregrinação artística", "um verdadeiro ritual". A maior parte do público que procura a Gioconda é formada pelos não-iniciados, ou como diz a matéria, "curiosos" que aceitam com resignação "o passo a passo em fila, como num ritual milagroso para tocar a imagem da Virgem Maria e depois descarregar a tensão que traziam no peito". Ficam por quinze segundos num silêncio comedido para depois dar lugar a outro fiel com máquina fotográfica. O jornalista Welliton Carlos (2005) acrescenta que, em sua maioria, os espectadores de Monalisa são apenas voyeurs da fama.

Encaram a Monalisa como participante perpétua do programa Big Brother das artes plásticas. Não querem saber se sua composição é mesmo revolucionária. Desejam apenas fruir o glamour da cena: quanto custa, se já foi roubada, se é grande ou pequena e qual motivo, afinal, de tanta fama.

O fetichismo artístico chegou a tal ponto que mesmo o Museu do Louvre, que possui outras tantas obras de Da Vinci, tem, preponderantemente, a sala da Monalisa lotada todos os dias e mais cinco milhões de visitantes sem poder ver a obra por ano. Ao percorrer as salas que levam à sala da obra em questão, o visitante atento pode até se espantar diante de sua simplicidade, comparada a outras obras italianas dos séculos XVI e XVII.

A romaria de pessoas em busca do glamour de algumas criações e de seus criadores procede semelhantemente com outras obras e artistas. Como se não bastasse ignorar o conjunto da obra do artista, os detalhes que lhe conferem riqueza e complexidade, há um gritante interesse por detalhes obscuros e sórdidos da vida do autor. Com efeito, um relacionamento que a sacralização pode incentivar, tais como o interesse exacerbado pelos detalhes sórdi- 
dos nesse contexto, o que marca não é a qualidade revolucionária da obra de Van Gogh, mas o fato de ele ter cortado a orelha e pintado Os girassóis; não se reconhece a obra de Frida Kalho por sua inserção no movimento surrealista, mas por ter uma saúde frágil e uma vida amorosa conturbada, Beethoven é ignorado como o músico que fez a ponte entre o Classicismo e o Romantismo, contudo é conhecido como compositor surdo (na verdade ele foi perdendo gradativamente a audição) da $9^{a}$ sinfonia. A lista poderia continuar se estendendo regida pela lógica que reduz a obra de arte e torna a vida do artista um festival de "fofocas históricas", que em nada contribuem para o desenvolvimento do senso estético.

Se retomarmos o lento, porém marcante processo de sacralização, será fácil vislumbrar os motivos que levaram o grande público a se afastar (ou ser afastado?) do contato prazeroso e significativo com a arte. Ao se organizar como campo social, o campo artístico providenciou medidas para legitimar seu poder e dominação e uma delas foi a exclusão das massas. Somente entendendo a gênese de todo esse processo de reserva de privilégios, e aprisionamento do discernimento estético é que se poderá contribuir para a compreensão de como os tesouros artísticos estão abertos e, ao mesmo tempo, interditos à maioria das pessoas.

Segundo a própria reportagem aqui utilizada, os fãs dos quinze segundos enxergam o todo sem antes verem os detalhes, pois não conhecem as regras do ponto de fuga, perspectiva, equilíbrio, mistura de cores, adequação de superfície ao suporte. Isso não quer dizer que os museus deveriam estar fechados ao grande público, mas que sem a posse dos devidos códigos de leitura e os meios para tornar possível sua apropriação, a arte, efetivamente não terá condições de pertencer a todos.

Em termos artísticos, não basta garantir a gratuidade aos eventos e espaços. De acordo com Bourdieu (1966), as estatísticas revelam que o acesso às obras culturais é privilégio da classe culta, e tal privilégio exibe a aparência de legitimidade, já que, por princípio, o acesso aos espaços e aos objetos é livre. Numa cidade como Goiânia-GO, essa verdade é perfeitamente aplicável: nela há vários museus com entrada franca, outras tantas obras de arte ao ar livre, concertos gratuitos que acontecem aos finais de semana, sessões de curtas e cine cultura a preços populares. Enfim, se a freqüentação por parte das camadas populares não acontece,

146 R. Faced, Salvador, n.12, p.139-150, jul/dez. 2007 
ou se acontece de maneira equivocada, como no exemplo da reportagem, é porque naturalmente essas camadas rejeitam as práticas culturais.

A esse respeito, Bourdieu (1966, p. 69) ressalta que,

Considerando que a aspiração à prática cultural varia como a prática cultural e que a 'necessidade cultural' reduplica à medida que esta é satisfeita, a falta de prática é acompanhada pela ausência do sentimento dessa privação; considerando também que, nesta matéria, a concretização da intenção depende de sua existência, temos o direito de concluir que ela só existe se vier a se concretizar. O que é raro não são os objetos, mas a propensão em consumi-los, ou seja, a 'necessidade cultural' que, diferentemente das 'necessidades básicas', é produto da educação: daí, segue-se que as desigualdades diante das obras de cultura não passam de um aspecto das desigualdades diante da Escola que cria a "necessidade cultural" e, ao mesmo tempo, oferece os meios para satisfazê-la.

Agora o autor toca de perto no segundo questionamento: como restabelecer esses laços já tão fragilizados? Haveria alguma chance de resgatar da "necessidade cultural", aqui entendida como possibilidade de fruição estética? Para esse autor, sim! E caberia à escola acabar com o sentimento de indignidade profunda (e de incompetência) que assombra os visitantes menos cultos, são "como que esmagados pelo respeito diante do universo sagrado da cultura legítima" bem como mantidos afastados dos museus. Ao pesquisar os museus de arte da Europa, Bourdieu (2003) percebeu que a parcela de visitantes que têm a atitude mais sacralizante em relação ao museu decresce muito fortemente, quando a posição social se eleva $(79 \%$ dos membros das classes populares associam o museu à imagem de uma igreja, contra $49 \%$ nas classes médias e 35\% nas classes superiores).

Com a pesquisa de Bourdieu e Darbel, ficou evidente que o caráter sagrado da arte e da cultura afeta a possibilidade da experiência estética. De maneira análoga, o espectador trava com as artes o mesmo tipo de relacionamento que teria com a religião: algo incompreensível, humanamente impossível de apreender, que deve ser respeitado inquestionável e irrefletidamente. Aquele que assim não proceder, ou se opuser a esses cânones, está sendo herege e profanando objetos sagrados. Os lugares e os produtores da cultura são considerados templos, ou igrejas em que

R. Faced, Salvador, n.12, p.139-150, jul/dez. $2007 \quad 147$ 
repousam os frutos da genialidade de seres portadores de dons sobrenaturais, acima dos reles mortais destinados às atividades produtivas que garantem a sobrevivência material.

Quem não recebeu da família ou da escola os instrumentos que somente a familiaridade artística pode proporcionar terá uma percepção da obra de arte valendo-se da experiência cotidiana e acabará no simples reconhecimento do objeto representado. "Em poucas palavras, para passar da camada primária dos sentidos que podemos penetrar com base em nossa experiência existencial", é necessário que se promova uma alfabetização estética do indivíduo. (BOURDIEU, 2003, p. 79)

Sem a devida iniciação à 'necessidade cultural', ou seja, à importância das artes como constituída e constituinte do ser humano, não haverá a menor possibilidade dos indivíduos que nunca experimentaram esse prazer dele sintam falta. O não-conhecimento da importância do capital cultural acaba por legitimar e reproduzir a lógica cruel de que o capital cultural vai para o capital cultural. Assim, os produtos da cultura erudita acabam circulando ciclicamente entre os membros legítimos da cultura erudita.

A sacralização da arte e do artista impregnou de tal forma o universo artístico que alguns homens egrégios se consideram "Os eleitos" para apreciar o belo por um dom da natureza, jamais como resultado de um aprendizado e familiaridade; "por algo que no limite nada tem a ver com berço e escola, dinheiro ou poder". Apoiados nessa convicção, julgam se distanciar e se distinguir das massas. Não só sacralizaram-se as obras e os autores como também os membros licenciados para delas se apossarem. Além de legitimar o conceito de dom na criação artística " como forma de naturalizar e esconder as relações de dominação " apresentase o discernimento estético como algo gratuito, inato, impossível de ser ensinado.

Quando se nega o vínculo entre cultura e educação, legitimase os privilégios herdados e a natureza dos homens que estão fadados ao desapossamento cultural. Bourdieu (2003, p.167) é enfático nesse sentido ao afirmar que:

Para que a cultura possa desempenhar sua função de legitimação dos privilégios herdados, convém e basta que o vínculo " ao mesmo tempo, patente e oculto " entre a cultura e a educação seja esquecido ou negado.

148 R. Faced, Salvador, n.12, p.139-150, jul/dez. 2007 
A idéia conatural de uma cultura de nascimento, de um dom cultural, outorgado a alguns pela natureza, pressupõe e produz a cegueira relativamente às funções da instituição que garante a rentabilidade da herança cultural, além de legitimar sua transmissão, dissimulando que ela desempenha tal função: a Escola é, com efeito, a instituição que por seus veredictos formalmente irrepreensíveis transforma as desigualdades diante da cultura, socialmente condicionadas, em desigualdades de sucesso, interpretadas como desigualdades de dons que são, também, desigualdades de mérito.

Ao se eximir do papel de criar a necessidade cultural, ao mesmo tempo em que provê os meios para satisfazê-la, a escola contribui para a disseminação de uma concepção mística sobre a experiência estética como graça de alguns eleitos. O papel da educação deve ser o de promover, de forma rigorosa e sistemática, desde os primeiros anos de escolaridade, o contato direto com as obras, ou pelo menos um substituto, que possa aproximar-se dessa experiência. Sem exercer esse papel, a instituição escolar abdica de um poder capaz de desafiar o monopólio da distinção culta (BOURDIEU, 2003). Essa instituição deveria desenvolver a função específica de criar as disposições que fazem o homem culto, incitando à pratica cultural aqueles que não a encontraram no seio familiar, pois "ao se omitir de fornecer a todos o que alguns recebem da família, o sistema escolar perpetua e sanciona as desigualdades iniciais" (BOURDIEU, 2003, p. 108). Caso assim não assuma essa função, o sistema escolar será negligente em sua primordial função: a de ampliar ao máximo as referências culturais de seus alunos, potencializando a leitura de diferentes linguagens artísticas.

Para finalizar este artigo, recorro a Snyders (1995), a fim de asseverar que, embora seja necessário um investimento massivo da escola em ensinar a disposição culta, os códigos de leitura das obras que permitirão uma melhor experiência estética, ela jamais deve esquecer de primar pelas "alegrias culturais". Para que a dor " da exclusão, da injustiça, da incerteza e da miséria - seja transmutada em esperança, não como descoberta, mas avivada na iniciação cultural, na experiência estética e nas vibrantes possibilidades de si sentir e conhecer como humanos. 
The assessment as artistic aesthesis experience:

between the nodes of the sacralization of art and artistic

\begin{abstract}
The presents study aims to contribute to a discussion about the teaching of art and one of its main roles: supply to the students aesthetic experiences by artistical appreciation. The clipping proposed analyses possible obstacle of this way by the focus of sacralization of art and artist, understood as fruit of a social-historical process of a relation net who substract and mystifies the creative and its appreciation activity. This process sacralized the works, authors and also the licensed members to take possession of them. Besides to of domination - introduced the aesthetic judgement as something innate, impossible to be thaught. It is up to school a massive investiment in teaching the provision of culture, codes of reading the works that will enable a better aesthetic experience, not forgething the primacy of "cultural joys".

KEYWORDS: Art - Study and teaching. Art - assennment.
\end{abstract}

\title{
Referências
}

BENJAMIN, Walter. Magia e técnica, arte e política: ensaios sobre literatura e história da cultura. 7. ed. São Paulo: Brasiliense, 1994.

BOURDIEU, Pierre. As regras da arte: gênese e estrutura do campo literário. São Paulo: Companhia das Letras, 1996.

BOURDIEU, Pierre. A reprodução: elementos para uma teoria do sistema de ensino. 2. ed. Rio de Janeiro: Francisco Alves, 1982.

BOURDIEU, Pierre. As regras da arte: gênese e estrutura do campo literário. São Paulo: Companhia das Letras, 1982.

Escritos de educação. Seleção, organização, introdução e notas de Maria Alice Nogueira e Afrânio Catani. Petrópolis, RJ: Vozes, 1998.

O amor pela arte: os museus de arte na Europa e seu público. São Paulo: Zouk, 2003.

Razões práticas: sobre a teoria da ação. Campinas: Papirus, 1996b.

CARLOS, Welliton. busca de Monalisa. Diário da Manhã, Goiânia, 20 jun. 2005. Cidades, p.1.

DURAND, José Carlos. Arte, privilégio e distinção: artes plásticas, arquitetura e classe dirigente no Brasil. São Paulo: Perspectiva, 1989.

FORQUIM, Jean Claude. A educação artística: para quê. In: PORCHER, Louis. Educação artística: luxo ou necessidade. São Paulo: Summus, 1982.

HAUSER, Arnold. História social da arte e da literatura. São Pau1o: Martins Fontes, 1998.

OLIVEIRA, Jô. Explicando a arte: uma iniciação para entender e compreender as artes visuais. Rio de Janeiro: Ediouro, 2001.

SANTAELlA, Lúcia. (Arte) $\mathbb{E}$ (cultura): equívocos do elitismo. 3. ed. São Paulo: Cortez, 1995.

SNYDERS, Georges. Feliz na universidade: estudo a partir de algumas biografias. Rio de Janeiro: Paz e Terra, 1995. 